\title{
The Role of Campus Basketball League in Promoting the Construction of Campus Culture
}

\author{
Zhi Liu \\ University of Electronic Science and Technology of China, Chengdu, Sichuan, 611731
}

Keywords: Basketball League; Sports Culture; Campus Culture

\begin{abstract}
The construction of campus culture plays an important role in the development of higher education. College basketball league, as a major form of sports culture construction, has important significance for the whole campus culture construction. In this paper, the corresponding topic research, the current college basketball league on the campus culture to promote the role of a detailed analysis.
\end{abstract}

\section{Introduction}

Basketball League is a major form of sports activities, for the development of sports culture has an important impact. Because of the characteristics of basketball itself, such as competition, cooperation, recreation and so on, it can promote the healthy development of college students' physical and mental health. The activity can not only improve the overall quality of students, but also enhance the cultural atmosphere of campus and promote campus culture Construction development.

\section{Basketball League and Campus Sports Culture}

Basketball competition as a popular college students welcome a sports in the actual construction of colleges and universities which has a very important position [1], and the basketball league, the campus culture for its construction is an important role in promoting. Since 1998 once a year since the league, is a well-known Chinese basketball tournament. The subject of education is relatively clear, coupled with its special cultural atmosphere, causing a lot of people and college students attention. In the stadium you can see a lot of meaningful slogans, like, "feel the culture, feel the basketball", "will play basketball as your dream" and so on, these languages to some extent inspired college students into the actual basketball culture In, and in constant understanding to receive their education. Therefore, the event gradually as a benchmark for ordinary college basketball tournament, its main form of organization, the specific form of operation has also been widespread concern.

At present, there is no specific understanding of sports culture, different researchers have their own understanding, but in the overall profile of its definition of sports culture is very similar. Campus sports culture is mainly: the students on the main position of education, and play a guiding role of teachers, and then comprehensively promote the development of students. At the same time to learn sports knowledge and enhance the overall quality of students as the main teaching content, so as to promote the campus spirit system and the material system of common development. Campus sports culture involves three levels: material, system and spirit of three levels.

As the main body of education, college students usually like to participate in a variety of amateur activities to enrich their own classroom life. Compared to the dull classroom activities, sporting events can attract the attention of college students. Sports activities not only help college students will be too much enthusiasm for the release of consumption, but also can help students to learn a variety of knowledge and skills, and thus enhance their overall quality [2]. To know, in a serious classroom after learning, to a relaxed and exciting sporting events, not only is the best part of interaction with students, but also a pleasure to get the psychological satisfaction. In this way, 
both to help students adjust the boring life, but also make the quiet campus full of vitality.

\section{The Influence of Basketball League Culture on Sports Spiritual Culture}

As the current stage by the diversity of the world's three major changes in college students have changed, as the main media positions in basketball, college basketball league to encourage students to re-establish qualified three view. In this platform, the corresponding management staff for the actual entry staff has some requirements, not only to be able to truly show their own charm, but also to establish the correct view of the three, and compliance with the relevant requirements. The relevant event will be based on the actual competition to the performance of the athletes to give the appropriate reward; for the more outstanding teams, coaches and so give a high degree of praise, these initiatives not only strengthen the pursuit of the honor value of the participants, but also show A fair sporting spirit.

Basketball League as an important base for training sports talents, through the cultivation of outstanding college students to achieve their own pursuit of goals [3]. Here, college students rely on their own efforts to achieve their own value, to complete their own tasks, and then on the other side of the students have an impact.

The current stage of social life is rich and colorful, in a complex era of the environment, some college students do not talk about academic heavy, and then in the pursuit of the target on the road gradually slack, college basketball as a student stage, "To set an example" and other ways to infect people around, and use their own actions to practice the concept of personal dreams to express the vitality of contemporary college students, as well as for the constant pursuit of things.

Material as an important basis for campus culture, the campus material culture is the school's basic hardware facilities, such as school construction equipment, teachers and teaching venues, etc., from the school's actual venues can be seen on the overall movement of the school atmosphere. In addition, the college basketball material culture includes the relevant organizational and management experience, there are some events will also involve the equipment and equipment, gifts, cheerleading and related fan activities, all belong to the college basketball league culture construction [4].

In the college sports league, athletes superb performance, not only attracted more students to join the basketball, but also led to a series of sports consumption. For example, students because of a basketball player's favorite, will buy related products, and then promote the prevalence of sports consumer goods. Moreover, for some sports powder, they will not only materially from the favorite players to imitate, and even worse and even do the same as the athletes head style, action, expression. These fanatical "Starchaser" behaviors making the sport-related sporting goods consumption gradually increased, and thus led to the sporting events related to the development of the industry [5].

College Basketball League has experienced decades of ups and downs, it is because of its relatively perfect structure of the system, which for many other college league is a good reference. For the school, with a sound system, and then on the students in the strict norms, and thus the formation of a good campus atmosphere, so as to ensure the normal work of colleges and universities, college activities have been normal implementation.

In the college basketball league's successful development, the major colleges and universities have also carried out the corresponding activities. At present, the organization of the basketball club as a group has not been widely popular [6], so how to use the basketball league in the current development of the specific basketball club into the current stage of the university first to take into account the problem.

\section{The Campus Cultural Significance of Campus Basketball League in Colleges}

In the quality of education, we must adhere to the principles of education and education, sports and education will be integrated, and then highlight the characteristics of education, and finally to cultivate a relatively more cultural characteristics of sports people [7]. In the whole education 
system, teachers, coaches and referees in the overall image to always maintain the "normal" characteristics, because they work for the actual education has a very important role. Basketball coaches play an important role in practical basketball training. It can carry out special training on the current basketball specialty classes, according to the current form of the corresponding tactical arrangements, but also to take the initiative and team members to communicate, and then stimulate the full combat fighting spirit. This will not only for the various colleges to cultivate the corresponding basketball main, coach staff, but also can also enhance the overall level of basketball skills, so as to lay the foundation for the actual basketball league. In daily life, as a people's teachers to lead by example, correct their own style of behavior, play a leading role in the lead. In order to better build the campus referee team, should do the corresponding referee work, and regularly organize the relevant meetings, and then give them the corresponding moral and responsibility constraints, so as to ensure that it in the actual referee process can play a full role, Do the appropriate referee work, and then set an example for students. Moreover, for the actual school students are to develop strict rules and regulations, and let it strictly obey the relevant referee sanctions, and then for the basketball league to create a more comfortable and harmonious environment. In addition, the athletes and league-related daily behavior is to conduct a rigorous assessment, and as the best sports moral standards.

With the regular holding of the basketball league in recent years, the formation of a basketball culture in the school atmosphere, students still have a new understanding of sports, and then on their own physical and mental health have a more in-depth understanding. Basketball is a kind of campus culture, its main value is to show people's freedom, comprehensive and healthy development, but also reflects the human health and psychological development of the main form of harmony, and then highlight the purpose of sports. The holding of the basketball league will involve a lot of activities, such as slogans involved, banners, basketball salons and other forms of activities, especially because of the league and the establishment of the organization and management department, after several years of development, now Have been gradually moving towards a professional point of view, from their actual performance can be seen these years of efforts and their love for the basketball league [8]. Basketball League audience is the students of the faculties, the league needs the equipment is also designed by their respective teams, such as team flag, slogans, etc., which show the cultural characteristics of their respective faculties. Of course, there are essential cheerleaders, which makes the basketball league scene is very lively, people excited. There are some other activities derived from the league activities in a variety of forms, and then contrast the atmosphere of the basketball league. These lively forms of activity is maximizing the cultural characteristics of the basketball league. So, in the university basketball league not only can better promote the development of the basketball league, but also for the campus culture into a new vitality. Similar to such activities, but also to help college students to slow down the pressure of learning, enrich the students' spare time, and then help students develop interest, physical fitness. According to the survey, due to the holding of the basketball league, students love the degree of basketball increased significantly, and the number of people interested in basketball is also rising, and some students because of the league's fanatical, and then choose to engage in basketball Of the profession. By the basketball league to bring students not only leisure, in which one, the actual insight of students is enhanced, imagination is also more abundant, the most important thing is that students overcome the difficulties of the determination of the fighting has been significantly improved.

Basketball League has been adhering to the principle of fairness and openness, and then to start a new ideological and moral education. From the beginning of the game has been uphold the original principle, and declared illegal punishment of illegal personnel, of course, these years have been doing so, it can be said that today's league has strict rules of the race. On the basis of uphold the rules of the league, but also requires students to establish their own principles of fairness and justice, insist on putting an end to some bad social atmosphere.

Cohesion is a collective force, the formation of this power needs in the values, ideas, habits and behavior, etc. to unify, only when people have a common goal, the common direction, cohesion can 
be better formed. Sports culture, it has a strong cohesion, this cohesion is also deeply demonstrated in the basketball league. Basketball competition, not only can make the faculties of the team cohesion increase, but also can promote the exchange between students and emotional interaction, and then resonate to produce collective consciousness. The establishment of the faculty of the faculties, for their respective faculty construction provides a strong backing, which is the best channel to train the best basketball team. After several years of actual competition, the team building more and more powerful, more and more solid technology, whether it is cheerleaders or new members to join, make the team building more full [9]. The team in the years of fighting, the feelings of internal members are between the more rich, the team's cohesion and more powerful.

School students in the school by watching the actual basketball tournament, not only can feel the team cohesion, but also produce a certain sense of identity, honor. Through the sport of basketball, the students' sense of honor, collective sense of cohesion and then for the actual school is to contribute to the power, which is shown by the University Basketball League campus culture.

\section{Conclusion}

In short, through the basketball league can not only promote the development of sports and cultural undertakings, but also can further promote the development of cultural undertakings in colleges and universities, which is the main meaning of college basketball league, and then cultivate a certain sports spirit of the top students.

\section{References}

[1] Ge Weidong. On the Promotion of Campus Basketball League to Campus Culture Construction [J]. Sport World, 2016, (05): 119-120 + 133. (2016-05-18) [2017-08-16].

[2] Tang Wanke. China's college basketball culture and the formation of the impact on campus culture [J]. Sports, 2016, (11): 99 +6. [2017-08-16].

[3] Guo Hao. Analysis of CUBA Chinese college basketball league and college campus culture construction [J]. Science and Technology Information, 2012, (01): 323. [2017-08-16].

[4] Chen Chenglin. University campus basketball culture status and countermeasures [J]. Sports World (Academic Edition), 2012, (06): 121-123. [2017-08-16].

[5] Li Kun. Analysis of college basketball on the campus culture construction [J]. Intelligence, 2012, (32): 210. [2017-08-16].

[6] Ou Shiwei. New era of university campus basketball culture construction path [J]. Journal of Fujian Radio \& TV University, 2013, (04): 84-86. [2017-08-16].

[7] Wang Qiang.Research on the Influence of Basketball on Campus Sports Culture in Colleges and Universities [J]. Journal of Small and Medium Business Administration and Technology (Shanghai), 2014, (08): 239-240. [2017-08-16].

[8] Huang Tian, Zeng Zhijun, Guo Nan. CUBA Basketball League on the campus culture construction influence [J]. Fujian Sports Science and Technology, 2015,34 (01): 51-52 + 56. [2017-08-16].

[9] Li Yunfeng. Journal of Hubei Correspondence University, 2015,28 (10): 33-34. [2017-08-16] On

the campus basketball culture construction on the college basketball team construction of the positive impact [J]. Journal of Hubei Correspondence University, 2015,28 (10): 33-34. [2017-08-16]. 